\title{
estudo da infância e desafios da pesquisa: estranhamento e interdependência, complexidade e interdisciplinaridade
}

\author{
maria letícia nascimento ${ }^{1}$ \\ universidade de são paulo - brasil
}

\section{resumo}

Considerar as crianças sujeitos históricos e de direitos, atores sociais, produtores de cultura é resultado de uma construção social, fundamentada em pesquisas realizadas pelo campo da sociologia da infância. O reconhecimento de que crianças constroem cultura vai se configurar a partir dos estudos desenvolvidos principalmente na década de 1990, sob a ótica de sua dinâmica histórica, cultural e social (QVORTRUP, 2002). Esses estudos têm defendido que a infância seja reconhecida como grupo específico que produz e reproduz a vida social, ou seja, que as crianças são seres históricos, sociais, que estabelecem relações com outras crianças e com adultos, como pessoas que participam da sociedade, ainda que de forma limitada, e são influenciadas por eventos políticos, econômicos, culturais, tecnológicos, dentre outros. Essa concepção, contudo, tem convivido com outros paradigmas, como o paternalismo, ou com concepções que fragilizam a condição de ser criança e mantém a ideia de passividade e, assim, de subordinação ao poder dos adultos. A infância, contudo, não pode ser abordada apenas pelo que as instituições adultas esperam, mas reconhecida como grupo específico que produz e reproduz a vida social. Pesquisar a infância, assim, significa lidar com relações e conteúdos complexos, que tanto podem focalizar a interdependência entre crianças e adultos quanto evidenciar as relações de poder estabelecidas nas relações geracionais. Ainda que sejam os adultos a estudar a infância, investigá-la a partir das crianças significa não ignorar que suas ações provêm da mesma multiplicidade de fatores presentes nas relações sociais. Além disso, admitir que forças econômicas e políticas interferem em seu cotidiano, assim como estabelecem fronteiras entre diferentes grupos de meninos e meninas, desafia e define caminhos interdisciplinares de investigação.

palavras-chave: infância; geração; interdisciplinaridade.

\section{childhood studies and research challenges: estrangement and interdependence, complexity and interdisciplinarity}

abstract

Considering children as historical subjects of rights, social actors, producers of culture is result of a social construction, based on research carried out by the field of sociology of childhood. The recognition that children construct culture is based on studies developed mainly in the 1990s, based on their historical, cultural and social dynamics (QVORTRUP; 2002). Childhood studies have advocated that childhood might be recognized as a specific group that produces and reproduces social life, that is, that children are historical and social beings that establish relations with other children and with adults, as people who participate in society, even if in a limited way, and are influenced by political, economic, cultural and technological events, among others. This conception, however, is coexisting with other paradigms, such as paternalism, or with conceptions that weaken the condition of child and maintain the idea of passivity and, therefore, of subordination to the power of adults. Childhood, however, cannot be addressed only by what adult institutions

\footnotetext{
${ }^{1}$ E-mail: mletician@gmail.com
} 
estudo da infância e desafios da pesquisa: estranhamento e interdependência, complexidade e interdisciplinaridade

expect, but recognized as a specific group that produces and reproduces social life. Researching childhood thus means dealing with complex relationships and content, which can both focus on the interdependence between children and adults, as well as evidence of the power relations established in generational relationships. Recognizing that is adult people who study childhood, research them means not ignoring that their actions come from the same multiplicity of factors present in social relations in general. Moreover, admitting that economic and political forces interfere with their daily lives, at the same time as they establish boundaries between different groups of boys and girls, are the challenges and defines interdisciplinary research paths.

keywords: childhood; generation; interdisciplinarity.

\section{estudios de la infancia y desafíos de la investigación: extrañamiento e interdependencia, complejidad e interdisciplinaridad}

resumen

Considerar a los niños como sujetos históricos e de derechos, actores sociales y productores de cultura es el resultado de una construcción social basada en la investigación realizada por el campo de la sociología de la infancia. El reconocimiento de que los niños construyen cultura va a configurarse a partir de estudios desarrollados, principalmente, en la década de 1990 bajo la óptica que considera su dinámica histórica, cultural y social (QVORTRUP, 2002). Dichos estudios han defendido que la infancia sea reconocida como un grupo específico que produce y reproduce la vida social, es decir, que los niños son seres históricos y sociales que establecen relaciones con otros niños y con adultos como personas que participan en la sociedad, aunque sea de manera limitada, y son influenciados por eventos políticos, económicos, culturales y tecnológicos, entre otros. Esta concepción, sin embargo, coexiste con otros paradigmas, como el paternalismo, o con concepciones que fragilizan la condición de ser niño y mantienen la idea de pasividad y, por tanto, de subordinación al poder de los adultos. Sin embargo, la infancia no puede ser abordada sólo por lo que las instituciones adultas esperan, sino que se reconoce como un grupo específico que produce y reproduce la vida social. Por lo tanto, investigar la infancia implica lidiar con relaciones y contenidos complejos que pueden centrarse tanto en la interdependencia entre niños y adultos como en evidenciar las relaciones de poder establecidas en las relaciones generacionales. Aunque son personas adultas las que estudian la infancia, investigarla significa no ignorar que sus acciones provienen de la misma multiplicidad de factores presentes en las relaciones sociales en general. Además, admitir que fuerzas económicas y políticas interfieren con su vida cotidiana, al mismo tiempo que establecen fronteras entre diferentes grupos de niños y niñas, desafía y define caminos interdisciplinares de investigación.

palabras clave: infancia; generación; interdisciplinariedad. 
estudo da infância e desafios da pesquisa: estranhamento e interdependência, complexidade e interdisciplinaridade

Quais são as virtudes e quais são as armadilhas da terminologia "estudos da infância"? [...] O conceito de infância amplia o campo de estudo para incluir não apenas indivíduos e grupos localizados em uma determinada categoria de idade histórica e culturalmente definida, mas também as circunstâncias variadas de suas vidas, incluindo as formas em que são definidas e tratadas por outros. Por outro lado, embora o campo enfatize variabilidade e mudança, o conceito de infância frequentemente tende a ser reificado. (THORNE, 2007, p.149)

Estudos da infância têm defendido que a infância seja reconhecida como grupo específico que produz e reproduz a vida social. Com características diferentes das dos adultos, as crianças, mesmo pequenas, são sujeitos ativos e competentes, cujas ideias e ações permeiam seus contextos sociais e as relações neles estabelecidas. Elas fazem parte de um mundo social, são influenciadas por ele e, ao mesmo tempo, o influenciam. Criam significados e vão dispondo "suas representações e crenças em sistemas organizados, isto é, em culturas" (SARMENTO; PINTO, 1997, p.20). Em outras palavras, as crianças são seres históricos, sociais, que estabelecem relações com outras crianças e com adultos, como pessoas que participam da sociedade, ainda que de forma limitada, e são influenciadas por eventos políticos, econômicos, culturais, tecnológicos, dentre outros. Romper com o paternalismo, com a tradicional concepção de criança universal, paradigmas que reforçam a imagem da infância vulnerável e imatura e que, assim, constituem instrumentos de invisibilização de meninos e meninas concretas e contextualizadas, e reconhecer a infância como categoria geracional vai permitir compreendê-la como parte da estrutura social, integrada e comparável com outros segmentos dessa estrutura (QVORTRUP, 2010).

Este artigo busca mapear concepções, conceitos, paradigmas que envolvem os estudos da infância, a partir de alguns pesquisadores, e, para tanto, está organizado em três segmentos: um primeiro, que busca recuperar o que tem sido dito sobre as crianças e a infância, numa linha sociológica, um segundo, que procura compreender, ainda que não exaustivamente, a força do paternalismo e de uma concepção negativa da infância, presente no cotidiano das práticas sociais, 
estudo da infância e desafios da pesquisa: estranhamento e interdependência, complexidade e interdisciplinaridade

um terceiro, que aponta aspectos da complexidade dos estudos da infância e propõe investigações interdisciplinares.

\title{
estudo da infância: retomando um ponto de partida
}

\begin{abstract}
Conhecer as 'nossas' crianças é decisivo para a revelação da sociedade, como um todo, nas suas contradições e complexidade. Mas é também a condição necessária para a construção de políticas integradas para a infância, capazes de reforçar e garantir os direitos das crianças e a sua inserção plena na cidadania activa. (SARMENTO, 2002, p. 01)
\end{abstract}

A epígrafe inspira e levanta a primeira das grandes questões que este texto pretende abordar: o que é - tem sido, pode ser - estudar a infância? Por que nos interessa "conhecer as 'nossas' crianças"? O que nos dizem as pesquisas sobre a infância? Ainda que tenha a impressão de que muitos dos pontos que vou trazer aqui já tenham sido abordados em diferentes textos, por vários autores, penso que seja importante recortar e destacar alguns aspectos, princípios, proposições, que se mantém pertinentes, embora pareçam, para muitos, superadas. Embora não vá trata-los de modo exaustivo, sua utilização parece fundamental para pensar a infância.

Os estudos da infância têm defendido que a infância seja reconhecida como categoria social geracional que compõe a estrutura social e, nessa linha, "as crianças (incluindo os adolescentes) são vistas como uma categoria social cujas condições sociais e vidas são objeto de pesquisa em igualdade de condições com outras categorias sociais" (JAMES et al., 2001 apud NÄRVÄNEN; NÄSMAN, 2004, p.72).

No entanto, conhecer nossas crianças remete a uma condição de estranhamento. Nas palavras de Jenks (2002, p.187): “a criança não é imaginada senão em relação a uma concepção de adulto, embora seja impossível criar uma noção precisa da adultez e da sociedade adulta sem primeiro tomar em consideração a criança". Ou seja, olhar as crianças e concebê-las, explica-las, conhecê-las é uma tarefa que os adultos assumem, reconhecendo que as crianças parecem semelhantes a eles, mas funcionam de modo diferente, isto é, constatada 
uma semelhança do ponto de vista físico, evidencia-se um estranhamento em relação ao modo pelo qual as crianças lidam com o mundo.

Segundo o sociólogo, "a criança, a infância, o comportamento infantil e as brincadeiras de crianças não poderiam ser entendidas adequadamente através dos mesmos mecanismos explicativos" (JENKS, 2002, p.196) utilizados para a compreensão do mundo adulto. A busca por explicações sobre as crianças, num primeiro momento, vai objetivar uma uniformização da infância, sustentada por dois pressupostos: a criança é um fenômeno mais natural do que social e a natureza infantil passa por um inevitável processo de maturação.

Nesse sentido, a infância é considerada como período transitório no qual meninos e meninas internalizam passivamente a cultura social, um tempo de passagem, e o percurso do desenvolvimento infantil está fundamentado nas mudanças nas disposições do indivíduo: "da imaturidade (por exemplo, sexual) à maturidade, da incompetência (por exemplo, cognitiva) à competência, da incapacidade (por exemplo, motora funcional) à capacidade, e assim por diante" (QVORTRUP, 2010, p.635).

Costuma-se atribuir a concepção de criança como um vir-a-ser à educação e à psicologia, mas, mesmo do ponto de vista da sociologia, verifica-se que a infância foi concebida como “época em que o indivíduo, tanto do ponto de vista físico quanto moral, não existe ainda, em que ele se faz, se desenvolve e se forma" (DURKHEIM apud SIROTA, 2001, p.9), ou seja, um período ideal para educar e socializar por meio da transmissão de valores, crenças e normas da sociedade, que seriam interiorizados passivamente pelas crianças. Nesta interpretação, as crianças eram vistas à parte da sociedade, e precisavam ser moldadas e guiadas por forças externas para tornarem-se seus membros (CORSARO, 2011).

A infância, nessa perspectiva, representa um tempo de espera, isto é, "As expectativas dos adultos sobre as crianças correspondem a colocá-las numa posição de espera. O destino das crianças é a espera - paciente, até tornarem-se adultas, para [...] ser parte da coletividade de cidadãos." (QVORTRUP, 2014, p.32) 
estudo da infância e desafios da pesquisa: estranhamento e interdependência, complexidade e interdisciplinaridade

A espera vai acontecer principalmente na escola, espaço que vai tornar-se prioritariamente 'o lugar' das crianças, de sua preparação para o futuro.

Romper com a tradicional concepção de criança universal, instrumento de invisibilização de meninos e meninas concretas e contextualizadas, é uma tarefa que vai se evidenciando a partir de pesquisas tanto sobre a invisibilidade da infância nos contextos sociais, de modo geral - afinal, a escola é o lugar da infância - quanto naquelas que investigam as vozes das crianças, suas relações inter e intrageracionais e suas brincadeiras.

Considerar, então, as crianças como sujeitos históricos e de direitos, atores sociais, produtores de cultura é resultado de uma construção social, fundamentada em pesquisas realizadas pelo campo da sociologia da infância. $O$ reconhecimento de que crianças constroem cultura vai se configurar a partir dos estudos desenvolvidos, principalmente na década de 1990, sob a ótica de sua dinâmica histórica, cultural e social (QVORTRUP, 2002).

Do ponto de vista internacional, foi estabelecido um novo paradigma: a infância como uma construção social e as crianças, como atores sociais (JAMES; PROUT, 1990, p.8-9), e a infância como fenômeno social (QVORTRUP, 1991), que fundamentou pesquisas realizadas no campo da sociologia da infância, que constataram que as crianças são sujeitos competentes (HUTCHBY e MORANELLIS, 1998), são atores sociais (MAYALL, 2002), são produtoras de culturas² (CORSARO, 2011). Como sintetizam Närvänen e Näsman (2004, p. 72) “Crianças e adolescentes também são vistos como atores que interpretam seu mundo, refletem e criam significado, são atores envolvidos na construção de suas próprias vidas e influenciam suas próprias condições".

Todo o conteúdo deste primeiro segmento parece bastante conhecido e, de certa maneira, tem constituído os discursos sobre a infância e sobre as crianças, das orientações oficiais às falas de professores e professoras, dos textos de

\footnotetext{
2 Na perspectiva da reciprocidade, para Corsaro (2011), as crianças retiram elementos, para a interação com outras crianças, da interpretação que fazem dos sistemas culturais adultos ao mesmo tempo em que as interações entre pares afetam a maneira como convivem com os adultos.
} 
pesquisadores aos trabalhos dos estudantes. Quase um mantra, repetido em diferentes oportunidades.

\title{
estudo da infância: paternalismo e senso comum
}

\begin{abstract}
Wartofski argumenta que as crianças são criadoras inventivas porque se envolvem em ações propositivas. Não acredito que essa afirmação seja difícil de substanciar, o problema talvez seja seu conhecimento para e pela sociedade, porque a tese das crianças como participantes na construção do mundo é radical suficiente para tornar-se uma ameaça à ordem social, a qual talvez deva esforçar-se para tratar as crianças como máquinas triviais ${ }^{3}$, a despeito da falsidade deste conceito. (QVORTRUP, 2011, p.206207)
\end{abstract}

O comentário à quinta tese da infância como fenômeno social apresenta, de modo breve e contundente, a dificuldade da admissão das crianças como atores sociais, trazendo a infância como ameaça à ordem social, não porque não tenha ainda passado pelo processo de socialização, como apontava Parsons (1991), mas porque as crianças são inventivas e propositivas.

Há poucos anos, durante uma aula, ouvi de uma estudante uma significativa questão: "professora, tudo isso que você está falando é para estudo, não é? As crianças não são assim: eu tenho filhos, trabalho com crianças e... não é bem assim..." Entre constrangida e interessada, ela formulou a questão que parece presente e forte, tanto no senso comum quanto entre os próprios pesquisadores, ou aspirantes a, e entre professores/as. Afinal, as crianças, sujeitos de direitos, atores sociais e produtoras de cultura são um construto teórico? O que tem impedido que resultados de pesquisas ${ }^{4}$ cheguem com toda sua potência ao cotidiano, ao menos da escola?

\footnotetext{
3 Expressão criada por Niklas Luhman (1991, p.25 e 38). Uma "máquina trivial" é aquela que sempre transforma inputs em outputs, do mesmo modo, contanto que sua função de transformação permaneça idêntica. "Crianças não são, porém, máquinas triviais - como nenhum sistema orgânico ou psíquico pode ser - sustenta Luhman, mesmo que os professores façam o seu melhor para transformá-las nessas máquinas quando as encorajam a responder questões com segurança, ou seja, utilizando tão somente os caminhos corretos (desejados)." (QVORTRUP, 2010).

${ }^{4}$ Investigação de Nascimento et al (2013, p.142), sobre grupos de pesquisa que utilizam a sociologia da infância como referência, verificou que "as investigações e os estudos desenvolvidos pelos grupos selecionados inspiram-se, em sua maioria, na perspectiva da agência, no cotidiano das crianças pequenas e nos métodos etnográficos."
} 
estudo da infância e desafios da pesquisa: estranhamento e interdependência, complexidade e interdisciplinaridade

Não é preciso ir muito longe para localizar, no lugar atribuído às crianças na sociedade, a escola, a representação dos papéis geracionais, como aponta Castro (2008, p. 6):

Os adultos/os especialistas creem, em geral, que podem, sem grandes dificuldades, saber do quê as crianças mais precisam aprender na escola, que sabem, melhor do que elas o que é bom para seu futuro, podem afirmar que aspectos do conhecimento lhes são mais relevantes. Neste sentido, acham 'natural' agirem como seus representantes em relação a suas necessidades educacionais, e estão cientes da sua superioridade em relação à definição do que lhes convém. Tal naturalidade se assenta sobre a prerrogativa assumida de uma direção unívoca na transmissão intergeracional, em que os mais velhos são os que devem transmitir conhecimento aos mais novos (Castro, 2006). Portanto, segundo essa lógica, os adultos são os transmissores, e as crianças, as receptoras.

Pode-se dizer que esse é um procedimento, uma norma e um resultado do confinamento das crianças em instituições específicas, que, ainda que voltadas à infância, deram voz principalmente aos adultos ${ }^{5}$. Se pode ser associado à concepção de infância como período de imaturidade, invocando, de certo modo, um contexto de proteção, a naturalização apontada no excerto oferece pistas para buscar esclarecimentos sobre o distanciamento entre discursos pautados pela literatura do campo e saberes presentes na sociedade. De acordo com Qvortrup (2002), a infância é uma categoria minoritária e as decisões paternalistas dos adultos são tomadas em nome de crianças e seus "melhores interesses".

Ainda que não se pretenda discutir exaustivamente, cabe levantar alguns pontos de destaque, dentre eles, o paternalismo. Retomando Qvortrup (2011, p. 210), no final do texto das nove teses, temos que: “o paternalismo é uma atitude característica, no sentido de uma estranha combinação de amor, sentimentalismo, senso de superioridade em relação à compreensão equivocada das capacidades infantis e marginalização". Deriva de uma atitude de cuidado extremado em relação às crianças e aos jovens, que, de certa maneira, traz embutida a ideia de controle, de tutela, que enviesa a proteção como direito. De acordo com Tomás (2014, p. 138), os principais pressupostos do paradigma do paternalismo são:

Posicionamento subalterno das crianças na sociedade, Poder e hierarquização das relações entre adultos e crianças, Centralidade da discussão assente em binómios: adulto/criança, direitos/deveres,

\footnotetext{
${ }^{5}$ Ver Narodowski (1999); Gimeno Sacristán (2005).
} 
autonomia/controlo. Lógica assente na dependência biológica e na imaturidade das crianças.

Manfred Liebel (2007), sociólogo alemão, pesquisador da infância latinoamericana, destaca duas modalidades de paternalismo: o tradicional, que determina a subordinação absoluta das crianças aos adultos, e o moderno, no qual são reservadas às crianças algumas zonas, separadas da sociedade dos adultos, com regras e normas, "onde a vida é relativamente segura e elas podem se desenvolver livremente, mas que não prevê qualquer influência sobre a sociedade adulta” (LIEBEL, 2007, p.115). Sintetiza: “em lugar do estranhamento próprio do paternalismo tradicional, [é atribuída] responsabilidade própria, mas sem participação". (LIEBEL, 2007, p.115).

Parece interessante destacar que, do ponto de vista da argumentação de Liebel (2007), o paternalismo moderno promove uma aparente participação das crianças nos espaços que lhes são atribuídos, mas esta tem um caráter limitado, ou seja, é tutelada. O sociólogo defende que é a participação efetiva das crianças que vai estabelecer uma contraposição ao paternalismo. Tendo como foco o movimento dos meninos trabalhadores da América Latina, argumenta que a possibilidade de organização e de manifestação de ideias e de posições, assegurada pela Convenção dos Direitos das Crianças' ${ }^{6}$, legitima a participação. Esta, considerada em duas dimensões: uma, as competências que possibilitam às crianças ter um papel ativo no mundo que as rodeia, e outra, sua posição na estrutura social, que vai possibilitar ou limitar que possam mesmo ter um papel ativo na sociedade.

Como contraste, "uma "sentimentalização", que busca separar as crianças do mundo adulto e protegê-las contra ele" (QVORTRUP, 2010, p.791). A explicitação dos paradoxos parece um caminho pertinente para lidar com a distância entre os achados dos estudos da infância e uma concepção naturalizada da subalternidade das crianças aos adultos. Qvortrup (2010) vai buscar um outro

\footnotetext{
${ }^{6}$ Cabe lembrar, como o fazem Qvortrup (2010), James (2007), Marre (2013), por exemplo, que a $\mathrm{CDC}$ reconhece direitos específicos para os primeiros 18 anos de vida das pessoas, e, ao mesmo tempo em que define que as crianças devem ser consultadas em relação àquilo que as afeta, por isso mesmo, delimita o alcance de suas vozes ao que as afeta diretamente (Art.12).
} 
estudo da infância e desafios da pesquisa: estranhamento e interdependência, complexidade e interdisciplinaridade

conceito, o de "indiferença estrutural" ou desatenção, de Kaufmann (2005, p.791), para complementar essa não consideração das crianças como sujeitos sociais, mas "como um fenômeno altamente privatizado", ou seja, responsabilidade dos pais, e não da sociedade, como um todo, isto é, não há sentimento de responsabilidade compartilhado sobre quais necessidades ou problemas da infância podem ser considerados sociais. Nas palavras de Casas (2006, p. 41, grifo no original),

Hay alto consenso sobre los derechos de los niños y niñas, pero baja intensidad a la hora de actuar: siempre debe haber alguna otra instancia a quien le toca hacer algo cuando los derechos de los niños/as son conculcados. Las políticas de infância nunca son políticas prioritarias... pueden esperar, tarde o temprano llegarán a adultos.

Pode-se destacar que tanto o paternalismo quanto a indiferença estrutural invisibilizam a infância e reforçam seu entendimento como uma "minoria" na perspectiva geracional. Além disso, ambos os conceitos alimentam o senso comum no sentido de menorizar a infância, ou seja, de manter somente nas mãos dos adultos as decisões sobre o que será melhor para as crianças. Tais decisões, como se argumentou até agora, não correspondem ao que se tem obtido por meio da pesquisa. Nas palavras de Tomás (2014, p. 136), “A infância é ainda perspetivada dentro de parâmetros de um estatuto minoritário, como um período etário onde os indivíduos requerem proteção porque sabem menos, têm menos maturidade, menos força e menos experiência, em comparação com os adultos".

Retomando os estudos da infância, as pesquisas com crianças proporcionam outra interpretação sobre as relações sociais estabelecidas entre adultos e crianças e/ou entre os grupos de pares infantis, modificando o entendimento dos processos pelos quais as crianças se apropriam dos mundos sociais nos quais vivem, ou seja, as crianças são compreendidas como coconstrutoras da sociedade (QVORTRUP, 2011; DAHLBERG et al, 2003, CHRISTENSEN; PROUT, 2005), como atores sociais. Cabe destacar ainda o conceito de agência7 social, que "constitui uma competência individual das crianças, e não um sinal de sua subordinação em relação aos adultos. Como

\footnotetext{
7 Quando falamos de agência, estamos referindo protagonismo? Uma das questões que mobiliza pesquisas atualmente é refletir sobre semelhanças e diferenças entre os conceitos de agência, presentes nos textos clássicos da sociologia da infância, europeus e norte-americanos, de protagonismo, predominante em textos dos estudos da infância sul-americana, e de participação.
} 
agentes, as crianças dão sua própria contribuição para a reprodução social e cultural" (QVORTRUP; CORSARO; HONIG, 2009, p.7).

Na linha do que foi dito até aqui, a contribuição dos estudos sobre agência das crianças, além de reconhecê-las como sujeitos e compreender a produção das culturas infantis, permite a captura de concepções, valores e rotinas dos adultos em relação à infância, evidenciando uma relação de reciprocidade e de interdependência entre as gerações (NASCIMENTO, 2011).

estudos da infância: complexidade e interdisciplinaridade

A "interdisciplinaridade" é comumente entendida como algo parecido com o surgimento de percepção e compreensão de um dominio de problemas por meio da integração de epistemologias, conceitos e métodos de diferentes disciplinas de alguma maneira nova. (ALANEN, 2012, p. 420)

A argumentação apresentada no segmento anterior aponta problemas para a constituição dos estudos da infância, indicando aspectos da complexidade desses estudos. A consolidação de um campo de produção de conhecimento sobre a infância, que parte de um olhar sociológico sobre as crianças, parece demandar mais tempo e mais pesquisa, além de apresentar outras questões como se vê a seguir.

Pesquisar a infância pode tanto focalizar a interdependência entre crianças e adultos quanto evidenciar as relações geracionais de poder estabelecidas. Ainda que sejam os adultos a estudar a infância, investiga-la a partir das crianças significa não ignorar que suas ações provêm da mesma multiplicidade de fatores presentes nas relações sociais. Além disso, admitir que forças econômicas e políticas interferem em seu cotidiano, assim como estabelecem fronteiras entre diferentes grupos de meninos e meninas, desafia e define caminhos de investigação.

James (2007, p. 262), a propósito de pesquisas realizadas com crianças, comenta que:

Embora novas abordagens no estudo da vida cotidiana da infância e das crianças tenham aberto um espaço teórico e conceitual no qual as crianças podem falar, como observadores participantes, sobre suas experiências 
estudo da infância e desafios da pesquisa: estranhamento e interdependência, complexidade e interdisciplinaridade

do mundo, isso não é por si só suficiente para garantir que suas vozes e seus pontos de vista sejam ouvidos.

Outra questão significativa, a limitada amplitude do campo e alcance da pesquisa da infância nas ciências sociais está presente em editorial do periódico Childhood, elaborado por Leena Alanen ${ }^{8}$, que refere à sessão de abertura de um congresso da Associação Europeia de Sociologia (ESA): “Uma das mensagens entregues aos participantes da conferência foi a firme visão da infância como uma fase preparatória para a vida adulta, isto é, a visão que era dominante nos anos pré-1990 - e, evidentemente, que ainda domina na sociologia geral." (ALANEN, 2017, p.7) E, ao reconhecer essa restrição, chama os pares para uma maior teorização da infância.

Esse movimento tem estado constantemente presente em diversos encontros e seminários no continente europeu, mas tem também se colocado presente no contexto latino-americano, como evidenciam publicações que buscam formas alternativas de colaboração acadêmica entre pesquisadores deste continente. Neste caso,

La complejidad que reviste pensar las infancias1 y las juventudes desde múltiples puntos de vista se evidenció desde el principio en las formas diversas de abordaje que traían como acumulado e interés los investigadores e investigadoras que se fueron vinculando a este colectivo, unos desde su situación social, otros como analizadores de problemas ligados a la estatalidad, la institucionalidad, la desigualdad. Pero todos y todas con una preocupación que procura no desligar conocimiento académico y política, conocimiento académico y transformación social. (ALVARADO; LLOBET, 2013, p. 28)

As diferentes possibilidades provocadas por estudos que pretendem enfrentar a complexidade da infância acabam por provocar novas necessidades, quem sabe, de estudos interdisciplinares. Se Pedagogia e Psicologia se completavam até há pouco tempo atrás, delimitando as fronteiras ${ }^{9}$ dos estudos da criança, muitas das questões da infância e das relações inter e intrageracionais vão requerer outros campos, outras disciplinas, outras abordagens para dar conta da investigação. Ou seja, reconhece-se que infância e criança são fenômenos complexos de fato, compreendê-los, não apenas parcialmente, obriga a consulta a

\footnotetext{
${ }^{8}$ Recentemente traduzido e publicado no periódico Zero a Seis, v. 19, n. 35, p. 3-10, jan-jun 2017.

${ }^{9}$ Ver Coll (1992); Warde (1997).
} 
pesquisadores de outras áreas disciplinares e o desenvolvimento de formas eficientes de comunicação e colaboração com eles (ALANEN, 2012). Pensar em estudos interdisciplinares significa trazer outros pontos de vista para a pesquisa. Nas palavras de Alanen (2012), precisamos ter uma sociologia da infância forte, sólidos estudos históricos da infância, uma geografia da infância bem-sucedida, e assim por diante, para fazer estudos da infância interdisciplinares prosperarem.

Para finalizar, cabe dizer que este é um texto que não acaba, mas que, ao contrário, pode provocar referência - e estudos robustos - a outros tantos conceitos, concepções, paradigmas, paradoxos, autores que atualmente se encontram sob o guarda-chuva dos estudos de infância. Que seja!

\section{referências}

ALANEN, L. Theorizing childhood. Childhood. v. 21, n. 1, p.3-6, 2014.

ALANEN, L. Disciplinarity, interdisciplinarity and childhood studies. Childhood. v.19, n. 4, p. 419-422, 2012.

ALVARADO, S.; LLOBET, V. Introducción. In: LLOBET, V. (org.) Pensar la infancia desde América Latina: un estado de la cuestión. 1. ed. Ciudad Autónoma de Buenos Aires: CLACSO, 2013. p.27-32.

CASAS, Ferrán. Infancia y representaciones sociales. Política y Sociedad, v. 43, n.1, p.2742, 2006.

CASTRO, L.R. A Politização (Necessária) do Campo da Infância e da Adolescência. Psicologia Política. v. 14, n. 7, 2008. Disponível em: <http:// pepsic.bvsalud.org/pdf/rpp/v7n14/v7n14a05.pdf>. Acesso em: 24 set. de 2017.

CASTRO, L. R. Admirável Mundo Novo: a cadeia das gerações e as transformações do contemporâneo. In: COLINVAUX, D.; LEITE, L. B.; DELL'AGLIO, D. D. (orgs.) Psicologia do Desenvolvimento: reflexões e práticas atuais. São Paulo: Casa do Psicólogo, 2006. p.249-268.

CASTRO, L.R. Re-visitando a infância contemporânea: passagens, possibilidades e destinos. COLOQUIO DO LEPSI IP/FE-USP, 3, 2001, São Paulo. Anales electronicos. Disponible en: <http:/ / www.proceedings.scielo.br/scielo.php?script=sci_arttext\&pid=MSC0000000 032001000300013\&lng=es\&nrm=abn>. Acesso em: 24 Set. 2017.

COLL, C. As contribuições da Psicologia para a educação: teoria genética e aprendizagem escolar. In: LEITE, L. B. (org.) Piaget e a Escola de Genebra. 2. ed. São Paulo: Cortez, 1992. p. 164-197

CORSARO, W. A. Sociologia da Infância. Trad. Lia Gabriele Regius Reis. Porto Alegre: Artmed, 2011.

DAHLBERG, G.; MOSS, P.; PENCE, A. Qualidade na Educação da Primeira Infância: perspectivas pós-modernas. Porto Alegre: Artmed, 2003. 
estudo da infância e desafios da pesquisa: estranhamento e interdependência, complexidade e interdisciplinaridade

FERNANDES, F. As trocinhas do Bom Retiro. In FERNANDES, F. Folclore e mudança social na cidade de São Paulo. 3. ed. São Paulo: Martins Fontes, 2004. p.193-317. GIMENO SACRISTÁN, J. O aluno como invenção. Porto Alegre: Artmed, 2005. HUTCHBY, I; MORAN-ELLIS, J. Situating Children's Social Competence. In: HUTCHBY, I; MORAN-ELLIS, J. (ed.) Children and social competence. Arenas of action. London, The Falmer Press, 1998. p. 7-26.

JAMES, A. Giving Voice to Children's Voices. Practices and Problems, Pitfalls and Potentials. American Anthropologist. v. 109, n.2, p. 261-272, june 2007.

JAMES, A.; JENKS, C.; PROUT, A. Theorizing Childhood. Cambridge: Polity Press, 2001. JAMES, A; PROUT, A. Constructing and Reconstructing Childhood. Contemporary issues in the Sociological Study of Childhood. London: Routledge Falmer, 1990.

JENKS, C. Constituindo a Criança. Educação, Sociedade e Culturas. Crescer e aparecer ou... para uma sociologia da infância. n. 17. Porto: Afrontamento, 2002. p.185-216.

KAUFMANN, F. X. Schrumpfende Geselsschaft: Vom Bevölkerungsruckgang und seine Folgen. Suhrkamp: Frankfurt, 2005.

LIEBEL, M. Paternalismo, participación y protagonismo infantil. In: CORONA CARAVEO, Y; LINARES PONTÓN, M. E. (coords.). Participación infantil y juvenil en América Latina. Universidad Autónoma Metropolitana, Childwatch International Research Network, Universidad de Valencia, México: 2007. p.113-146.

MARRE, D. Prólogo. De infancias, niños y niñas. In LLOBET, V. (org.). Pensar la infancia desde América Latina: un estado de la cuestión. 1. ed. Ciudad Autónoma de Buenos Aires: CLACSO, 2013. p.9-25.

MAYALL, B. Towards a Sociology for Childhood: Thinking from Children's Lives. Buckingham: Open University Press, 2002.

NARODOWSKI, M. Infancia y poder: la conformación de la pedagogía moderna. 2. ed. Buenos Aires: Aique, 1999.

NÄRVÄNEN, Anna-Liisa; NÄSMAN, E. Childhood as generation or life phase? Young - Nordic Journal of Youth Research, v. 12, n. 1, p.71-91, 2004.

NASCIMENTO, M. L. B. P. (coord) et al. Infância e Sociologia da Infância: entre a invisibilidade e a voz. Relatório Científico. São Paulo: FEUSP, 2013.

NASCIMENTO, M. L. B. P. Reconhecimento da sociologia da infância como área de conhecimento e campo de pesquisa: algumas considerações. In: FARIA, A. L. G de, FINCO, D. Sociologia da Infância no Brasil. Campinas: Autores Associados, 2011. p.3754.

PARSONS, T. The Social System. 2. ed. London: Routledge, 1991.

PINTO, M.; SARMENTO, M. J. (coord.) As crianças: contexto e identidades. Braga: Centro de Estudos da Criança - Universidade do Minho, 1997. (Colecção infans).

QVORTRUP, J. Visibilidades das crianças e da infância. Linhas Críticas, Brasília, v. 20, n. 41, p. 23-42, jan./abr. 2014.

QVORTRUP, J. Nove teses sobre a infância como um fenômeno social. Pro-posições. Campinas, v. 22, n. 01 (64), p. 199-211, jan./abr., 2011.

QVORTRUP, J. Infância e Política. Cadernos de Pesquisa, v.40, n.141, p.777-792, set./dez. 2010.

QVORTRUP, J.; CORSARO, W. A.; HONIG, M-S. Why Social Studies of Childhood? An introduction to the Handbook. In QVORTRUP, J., CORSARO, W. A., HONIG, MS. The Palgrave Handbook of Childhood Studies. London: Palgrave, 2009. p.1-18. 
QVORTRUP, J. Sociology of Childhood: Conceptual Liberation of Children. In: MOURITSEN, F.; QVORTRUP, J. (Eds.) Childhood and Children's Culture. Odense: Odense University Press, 2002. p. 43-78.

QVORTRUP, J. Childhood as a Social Phenomenon: An introduction to a Series of National Reports. Eurosocial Report. Vienna: European Centre, v.36, 1991.

SARMENTO, M. J. As culturas da infância nas encruzilhadas da 2. modernidade. In: SARMENTO, M. J.; CERISARA, A. B. Crianças e miúdos: perspectivas sociopedagógicas da infância e educação. Porto, Portugal: Edições ASA, 2004. p.9-34.

SIROTA, R. Emergência de uma sociologia da infância: evolução do objeto e do olhar. Cadernos de Pesquisa. São Paulo: Fundação Carlos Chagas, n. 112, p. 7-31, mar./ 2001.

THORNE, B. Crafting the interdisciplinary field of childhood studies. Childhood. v. 14, n. 2, p.147-152, 2007.

TOMÁS, C. As culturas da infância na educação de infância: um olhar a partir dos direitos da criança. INTERACÇÕES. n. 32, p.129-144, 2014.

WARDE, M. J. Para uma história disciplinar: psicologia, criança e pedagogia. In: FREITAS, M. C. (org.) História Social da Infância no Brasil. 2. ed. São Paulo: Cortez, Bragança Paulista: USF, 1997. p. 289-310

recebido em: 26.09 .2017 aceito em: 12.11 .2017 